LA-UR- 96: 3675

\begin{tabular}{l|l} 
Title: & $\begin{array}{l}\text { EXAMPLE OF SCATTERING NOISE IN } \\
\text { RADAR DATA INTERPRETATION }\end{array}$
\end{tabular}

Submitted to:

Gregory H. Canavan, DDP

Q6826000

Author(s):

03 TI

For discussions outside the Laboratory with the Air Force

Scientific Advisory Board

Date: October 1996

DISTRIBUTION OF THIS DOCUMENT IS UNUMUTEO

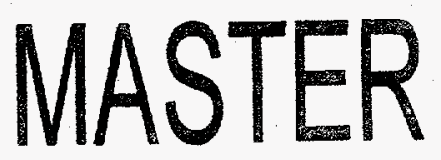

Los Alamos

NATIONAL LABORATORY

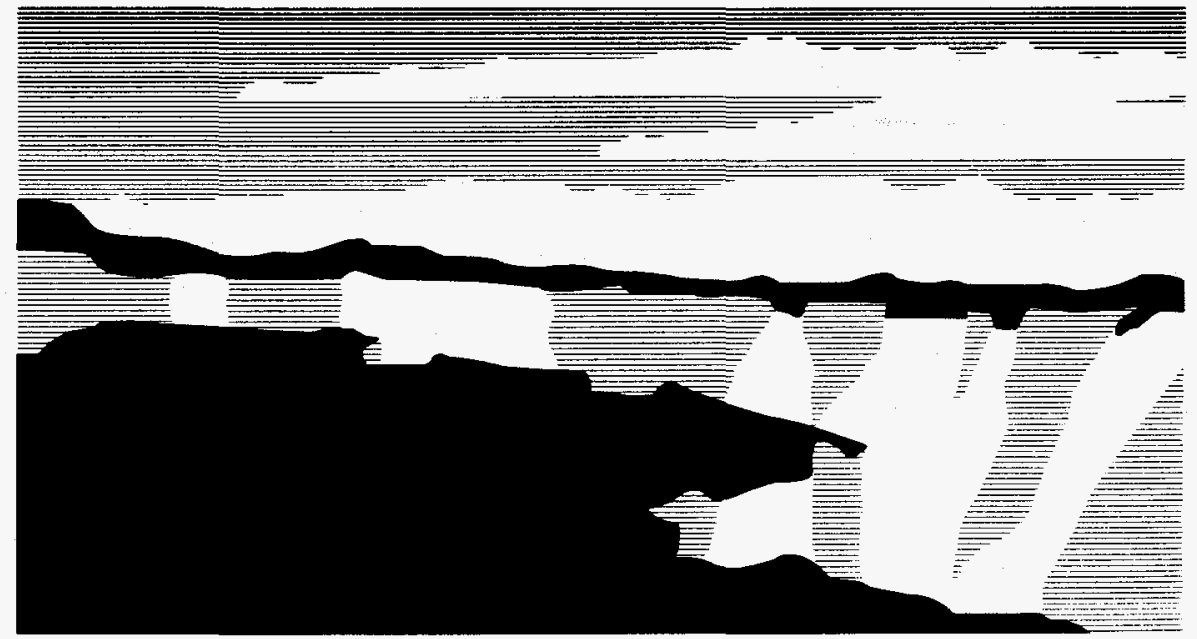

Los Alamos National Laboratory, an affirmative action/equal opportunity employer, is operated by the University of California for the U.S. Department of Energy under contract W-7405-ENG-36. By acceptance of this anticle, the publisher recognizes that the U.S. Government retains a nonexclusive, royalty-free license to publish or reproduce the published form of this contribution, or to allow others to do so, for U.S. Government purposes. The Los Alamos National Laboratory requests that the publisher identify this article as work performed under the auspices of the U.S. Department of Energy. 


\section{DISCLAIMER}

This report was prepared as an account of work sponsored by an agency of the United States Government. Neither the United States Government nor any agency thereof, nor any of their employees, make any warranty, express or implied, or assumes any legal liability or responsibility for the accuracy, completeness, or usefulness of any information, apparatus, product, or process disclosed, or represents that its use would not infringe privately owned rights. Reference herein to any specific commercial product, process, or service by trade name, trademark, manufacturer, or otherwise does not necessarily constitute or imply its endorsement, recommendation, or favoring by the United States Government or any agency thereof. The views and opinions of authors expressed herein do not necessarily state or reflect those of the United States Government or any agency thereof. 


\title{
EXAMPLE OF SCATTERING NOISE IN RADAR DATA INTERPRETATION
}

\author{
Gregory H. Canavan
}

Radar data interpretation typically assumes well behaved, known particle distributions. Those assumptions are at variance with the unknown angular scattering characteristics of the particles measured. This note gives a simple example of how those characteristics complicate data interpretation.

Model. A particle of area $\mathrm{A}$ is assumed to produce a return signal

$s=\mathrm{KA}$,

where $\mathrm{K}$ is a random variable that simulates the variation of the particle scattering cross section with orientation. If the probability density function (pdf) of $K$ is $q(K)$ and the pdf of $A$ is $p(A)$, the pdf of $s$ is

$$
r(s)=\int d K q(k) \int d A p(A) \delta(s-K A),
$$

where the delta function ensures consistency with Eq. (1), which can be simplified to

$$
r(s)=\int d K q(k) p(s / K) / K \text {. }
$$

While it is possible to proceed further formally, it is useful to chose specific examples for $q$ and p. Here, both are taken to be exponentials, which can closely approximate most pdfs of interest. Thus, Eq. (3) becomes

$$
r(s)=\int d K b e^{-b K} a e^{-a s} / K / K=\int d K / K a b e^{-(b K+a s / K)},
$$

which with the change of variables $y=b K, c=a b$ reduces to

$$
r(s)=\int d y c / y e^{-(y+c s / y)} \text {. }
$$

Results. The attached figure shows $r(s)$ for various values of $c$. If it is assumed that $a=1$, i.e., unit amplitude fluctuations, $\mathrm{c}$ can be viewed as a measure of the fluctuations due to scattering. Small c corresponds to weak scattering, where the relationship between $s$ and $r(s)$ is almost linear, and could be used to deduce the structure of $r$ from a number of measurements of $s$. For $\mathrm{c} \approx 1, \mathrm{r}$ is larger at small $\mathrm{s}$, but smaller at large $s$, which could be used to determine $\mathrm{r}$, if $\mathrm{c}$ was known. For $\mathrm{c}$ large, $\mathrm{r}$ is slightly smaller at small $\mathrm{s}$, and much smaller at large $\mathrm{s}$. For this condition, large scattering noise, it would be difficult to infer much about the particle sizes, as their signal is much smaller than that from the scattering noise.

Perhaps the main result from this model is the observation that in Eq. (5), for these pdfs, a and $b$ only occur in the product $c$; they do not appear separately, which means measurements of the pdf $r$ as a function of $s$ could be used to infer $c$, but they could not be used to infer $a$ and $b$ separately. The previous paragraph discussed possible means of inference of a from $\mathrm{c}$ under the assumption that a is essentially know, but if that is the case, there is no need for a measurement of it. This coupling of $\mathrm{a}$ and $\mathrm{b}$ is a limitation on models used to infer particle distributions, $\mathrm{a}$, 
from return signals, $r$. Since $a$ and $b$ are coupled, such an inference is not possible with the class of models discussed here. The exponential functions treated above are the most common pdfs, but for Gaussian pdfs, the exponents also combine to produce a signal variance that depends on the product of the variances of the particle area and scattering, not on their separate values.

Summary and conclusions. The assumptions of well behaved, known particle distributions used to interpret radar data are at variance with the unknown angular scattering characteristics of the particles measured. This note solves an analytic example of how those characteristics complicate data interpretation. The model treats randomness in particle sizes and scattering. It shows that for the main pdfs encountered in practice, the variances of the particle sizes and scattering only occur as the product. Since they do not appear separately, measurements of the pdf of the return signals could not be used to infer particle distributions separately. That limits how such models can be used to infer particle distributions from return signals. 


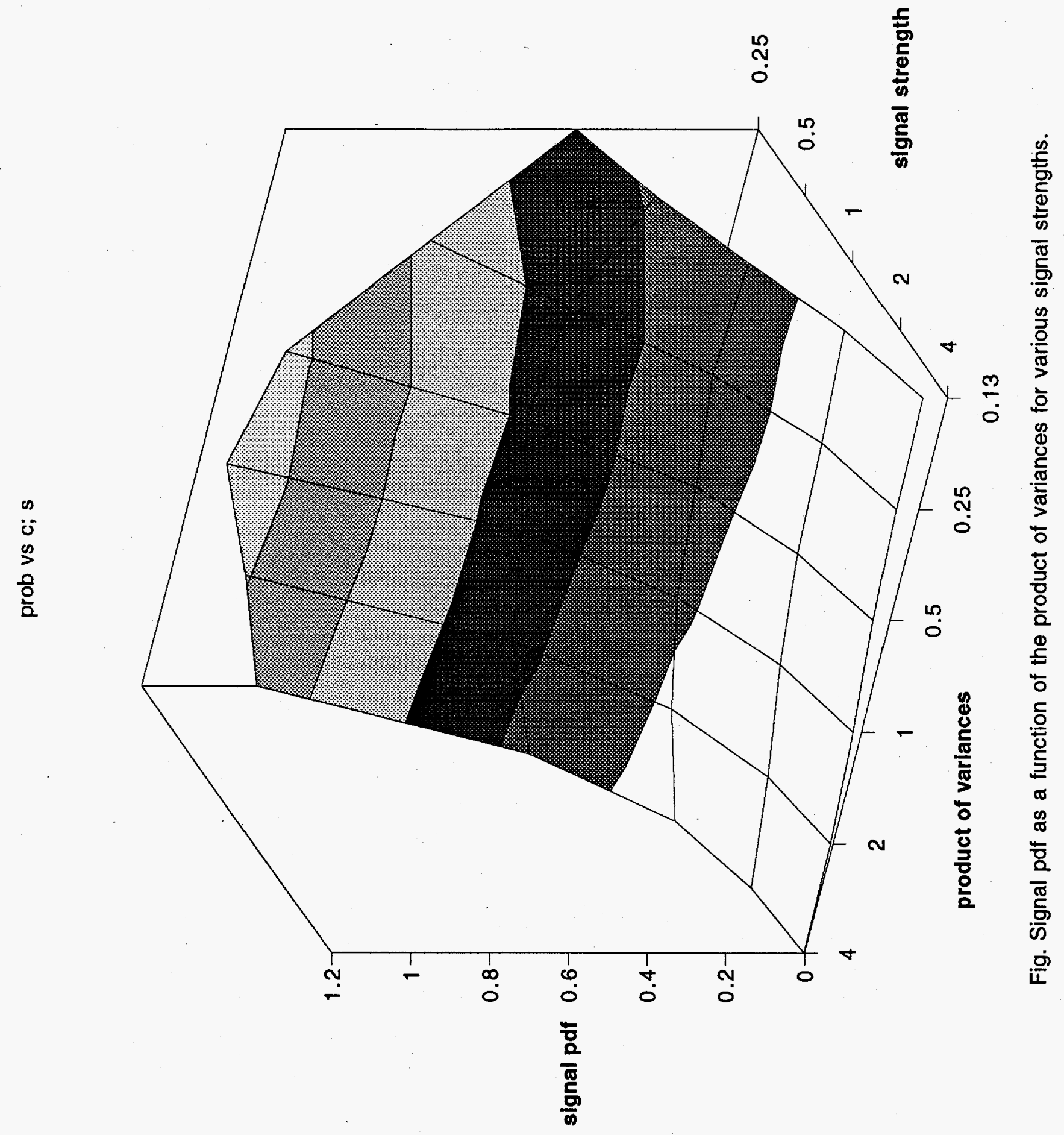

